\title{
Amor carnal, amor platónico en el Banquete
}

\author{
Fleshly love, platonic love in the Symposium
}

\author{
Por: María Angélica Fierro \\ Departamento de Filosofía \\ Instituto de Filosofia "Dr. Alejandro Korn" \\ Facultad de Filosofía y Letras \\ Universidad de Buenos Aires \\ CONICET \\ Buenos Aires, Argentina \\ Email: msmariangelica@gmail.com \\ ORCID: 0000-0002-9805-2081
}

Fecha de recepción: 12 de marzo de 2018 Fecha de aprobación: 8 de agosto de 2018 Doi: 10.17533/udea.ef.n59a09

Resumen. Me propongo mostrar aquí que en el Banquete Platón presenta consideraciones sobre la estima en que se tiene al cuerpo en apariencia contradictorias, pero en realidad complementarias. Las tres tesis centrales de la presente interpretación son: a) Que el cuerpo es esencial para activar el "éros", en tanto la atracción sexual hacia los bellos cuerpos es el modo más natural de comienzo de la experiencia erótica. b) Que el ascenso a la belleza en sí implica desapego de un cuerpo en particular para llegar a una apreciación de este desde una comprensión más amplia. c) Que el tipo de relación amorosa que establece Sócrates con jóvenes bellos muestra que la expresión fisica de "éros" nunca es totalmente erradicada, sino que, por el contrario, se convierte en un punto fundamental de reconexión con la carencia constitutiva de "éros".

Palabras clave: Platón, Banquete, amor, desapego, cuerpo

Abstract. Here I aim to show how the views on the body in Plato's Symposium must be considered not as contradictory but as complementary. The three main thesis of this paper are: a) The body is essential for the triggering of "erôs", insofar as sexual attraction to beautiful bodies is the most natural way in which anyone can start to develop an erotic experience. b) The ascent towards beauty itself implies detachment from a particular body as such in order to move to an appraisal of it from a wider, more general understanding. c) Additionally, the loving relationship between Socrates and beautiful young men shows that the physical dimension of "erôs" is never completely eradicated by Plato but, on the contrary, it works as an essential trigger of desire.

Key words: Plato, Symposium, love, detachment, body

* El presente artículo hace parte de la producción del Proyecto de Investigación Plurianual 2015-2017 (PIP no.112 20150100933 KS3) bajo mi dirección, del Grupo de Investigación, "La concepción de philosophía en Platón y sus desarrollos en el pensamiento helenístico", financiado por el Consejo Nacional de Investigaciones Científicas y Técnicas (CONICET), Argentina. Asimismo, del Proyecto de Investigación 2018-2019 "Consideraciones platónicas sobre lo irracional y la manía en algunos diálogos de madurez y en el Fedro" que actualmente desarrollo en tanto Investigadora Independiente de

Cómo citar este artículo:

MLA: Fierro, María Angélica. “Amor carnal, amor platónico en el Banquete”. Estudios de Filosofía 59 (2019): 183-212.

APA: Fierro, M. A. (2019). Amor carnal, amor platónico en el Banquete.. Estudios de Filosofía, 59, 183-212.

Chicago: María Angélica Fierro. “Amor carnal, amor platónico en el Banquete”. Estudios de Filosofía n. 59 (2019): $183-212$. 
la misma institución. Agradezco las observaciones de los árbitros anónimos, especialmente las detalladas y constructivas sugerencias de uno de ellos. La presente es una versión ampliada y reformulada de Fierro (2013c, pp. 258-262) y Fierro (2015a, pp. 125-132).

A mi madre y a mi padre

Oh, amigo, entiende a tu cuerpo; es como el océano, lleno de preciosos tesoros. Abre tu cámara secreta $Y$ enciende su lámpara.

Mirabai (Larsson, 2008, p. 112)

There is one place where her absence comes locally home to me, and it's a place I can't avoid.

I mean my own body. It had such a different importance while it was the body of H's lover.

Now it's like an empty house.

C.J. Lewis (1964, p. 5)

\section{Introducción ${ }^{1}$}

Diversos diálogos platónicos evocan a menudo la figura de un Sócrates quien, cual el sátiro Marsias, demuestra un intenso deseo sexual ante la presencia de los bellos muchachos así como también su interés y astucia para aproximarse a ellos y captar su atención con la melodía hipnótica de sus discursos (215b7-e4). ${ }^{2}$ Puesto que, a primera vista, su comportamiento en nada difiere del cortejo del típico amante de la época, esto haría suponer que tampoco deberían ser distintos sus objetivos, a saber que el joven consienta a la gratificación de este amor carnal. ${ }^{3}$ Mas Sócrates,

1 Sobre el tema del cuerpo en Fedro y el Fedón vid. Fierro (2013a, pp. 27-50) y (2013b, pp. 7-42) respectivamente.

2 Las traducciones del texto platónico son mías según la edición de Burnet (1899-1906). En el caso del Banquete refiero directamente a los números de los pasajes mientras que para el resto de los diálogos platónicos se antecede con abreviaturas usuales de los diálogos platónicos según el $L S J$.

3 La discusión sobre éros tanto en el Banquete como en el Fedro tiene como marco de referencia la relación homoerótica, que era habitual en la élite intelectual ateniense. Según los códigos de esta un hombre mayor y avezado —el amante (erastés) cortejaba al amado (erómenos), quien era un agraciado y talentoso jovencito, es decir, un paidiká (adjetivo sustantivado neutro plural relacionado con la palabra paîs - "niño"-, cuyo significado literal sería "cosas propias de un niño" y utilizado con el 
átopos una vez más, se escabulle del lugar esperado: no solo no intenta concretar físicamente sus fogosos anhelos sino que con los ardides de sus argumentos, logra que el bello joven se encuentre sorpresivamente desplazado del lugar esperado, puesto que de ser el preciado objeto de seducción se siente, en cambio, seducido, incluso físicamente, por este extraño individuo, quien no es, además, precisamente guapo ni se encuentra en la flor de la edad. ${ }^{4}$ En tal sentido, el Banquete representa una magistral puesta en escena de este complejo comportamiento de Sócrates respecto de la atracción que experimenta en su cuerpo - el cual se manifiesta entonces como "cuerpo amante" — hacia la belleza física de los jovencitos ${ }^{5}$ — cuyos cuerpos $^{6}$ operan entonces a su vez como "cuerpos amados", a la vez que activa

sentido singular de "querido" [cf. LSJ uv. paíd-euma III.2]; el amado no era en realidad un niño sino un "adolescente" [meirakiskos]). El amante le ofrecía, a cambio de los favores sexuales del jovencito, su guía para alcanzar la "excelencia o virtud" (areté), es decir el éxito individual y público según la concepción griega más corriente. Para una descripción in extenso de la relación homoerótica en Grecia antigua véase la fundamental obra de Dover (1978) y, más recientemente, el libro sobre el erotismo en general de Kilmer (1993). En relación a la significación educativa de la relación erastés-erómenos puede mencionarse la todavía útil reseña de Marrou (1985, pp. 46-57). En cuanto a las consecuencias políticas del modo en que se conducía la relación homoerótica vid. Calame (2002, pp. 93-115), Davidson (1997, pp. 250-277), Dover (1978, p. 19-41) y Foucault (1984, pp. 172-208).

4 Dado que la fecha dramática del Banquete suele establecerse en el 416 a.C., el personaje de Sócrates tendría en la ficción un poco más de cincuenta años - Sócrates muere en el 399 a.C. cuando tenía circa setenta años-; sobre su proverbial fealdad $c f$. Thaet. 143e7-9. A la natural repulsión de los jóvenes por la intimidad erótica con hombres viejos alude Agatón al afirmar en 195b1-2 que Éros, en tanto es "el más joven de los dioses", huye presuroso de la senectud. A este respecto puede también citarse la elocuente descripción al respecto en el Primer Discurso de Sócrates en Phdr. 240d4-e2: "Pero al [joven] amado, en igual tiempo de mutua compañía, ¿al brindarle qué tipo de consuelo y qué placeres conseguirá que no llegue a un grado extremo de repulsión, al ver un semblante más viejo y ya no en la flor de la edad, con las otras cosas concomitantes a esta, cosas que no son agradables de escuchar ni siquiera en palabras, ni qué decir de encontrarse continuamente en la obligación de llevarlas a los hechos..." En la poesía arcaica ya se refleja el sentir popular de aprecio de los goces de la plenitud corporal y los lamentos ante su pérdida por la decadencia física inevitable en la vejez (vid. García Gual, 2006, pp. 43-45 a propósito de la reconstrucción de un poema entero de Safo al respecto, a partir de dos fragmentos papiráceos, uno de 1922 y otro de 2004).

5 Aunque la idea actual de belleza difiera de la de la de simetría y proporción de la Grecia clásica (Konstan 2012, pp. 146-148), comparte con ella el ingrediente fundamental de que el sustantivo abstracto kállos refería sobre todo a la belleza física que despierta el deseo erótico, aunque también pudiera referirse a la belleza en contextos no amatorios (Konstan, 2012, pp. 143-145); el adjetivo kalós, en cambio, tenía a menudo el sentido más amplio de "noble", cercano al de "bueno" — agathós—. Concluye así este autor que el ideal de belleza física de los griegos, en oposición a la comprensión estándar que de él se tiene, estaba, pues, más relacionado con un cuerpo vivo, atractivo y bien proporcionado como el de Marilyn Monroe que con la blanca simetría estatuaria de la diosa Artemis (Kosman, 2012, p. 148).

6 En este trabajo entendemos que en Banquete sôma refiere principalmente —en oposición a la concepción homérica de un cuerpo vivo no-unificado o mero cadáver, junto con la de una psyché reducida a último aliento o a un "doble-fantasma" de cada cual en el más allá (Snell, 1953, pp. 1-22) — a un concepto 
también en ellos el éros. ${ }^{7}$ En efecto en esta obra platónica, por una parte, Sócrates no esconde su deseo de estar cerca de los más bellos del momento, como es el caso de Agatón y sobre todo de Alcibíades, ni tampoco intenta disuadirlos de que busquen la cercanía física con él. No obstante, después de que el deseo erótico ha surgido en los hermosos, el hijo de Fenareta no procura satisfacerlos - ni satisfacerse- a través de la consumación física, sino que frustra sus expectativas en tal sentido y les ofrece en cambio discursos que pongan en evidencia su ignorancia y abran para ellos una nueva comprensión.

El propósito del presente trabajo es mostrar que en el Banquete, a través de los distintos discursos sobre Éros y de modo más cabal en el de Sócrates/Diotima, Platón nos proporciona claves respecto de esta compleja consideración del deseo en y por el cuerpo, la cual concierne a todos los humanos pero que únicamente el filósofo, representado aquí por Sócrates, comprende cabalmente y es capaz de desplegar en todas sus dimensiones. De acuerdo a la interpretación aquí propuesta, mostraremos que en este diálogo consagrado a descifrar la naturaleza de Éros, en el "amor platónico", si bien idealmente se evita la concreción en el encuentro sexual, ${ }^{8}$ el cuerpo, ya sea en tanto amado o en tanto amante, es el activador natural del deseo por la belleza y en tal sentido constituye un instrumento precioso para iniciar la

de "cuerpo físico" captable a través de la sensopercepción, e inicialmente al "cuerpo humano", si bien en algunos casos es extensible a una noción más general y de proyección cósmica (sobre todo en el caso del discurso de Erixímaco). Este concepto de cuerpo se acuñaría en los siglos IV y V a.C. en paralelo - y no como remanente- del de psyché como "interioridad" (Holmes, 2010, pp. 5-8 contra Snell, 1953, pp. 1-22). Además, a través de sus formulaciones de la teoría de la metempsicosis, Platón desarrolla en su modelo antropológico otro elemento característico de la concepción del cuerpo forjada en el período clásico: que este se convierte en motivo de responsabilidad ética en la persona encarnada (Holmes, 2010, pp. 15; 171-177).

7 La concepción corriente de éros en la cultura griega implicaba el deseo sexual por un individuo en particular del que se estaba enamorado (Dover, 1980, p. 2). Por ser éros experimentado como una fuerza actuante desde afuera, los griegos - y entre ellos Platón - lo consideraban no solo como una emoción —éros - sino asimismo como una divinidad - Éros - retratada artísticamente en la cerámica de la época como un joven alado, quien eventualmente arroja flechas amorosas a sus víctimas. Por este motivo no es siempre claro diferenciar en el texto platónico entre una y otra perspectiva, sumado a que en la escritura no existía aún una distinción entre mayúsculas y minúsculas. En el presente trabajo hemos utilizado éros cuando nos estamos refiriendo más propiamente a la emoción y Éros cuando se trata del "dios" (theós) o la "divinidad" (daímon). Conscientes de la complejidad semántica del término hemos utilizado en la mayoría de los casos directamente el término griego, aunque a veces recurrimos a la traducción más tradicional: "amor" o "Amor".

8 En tal sentido leemos en el DRAE "Amor platónico: amor idealizado y sin relación sexual". Nos ocuparemos aquí de en qué sentido es carnal el éros platónico, más allá de que acordemos que la intención última de Platón en el Banquete es ofrecer una "teoría del amor", al cual describe como "deseo de poseer lo bueno para ser felices" (Boeri, 2016, p. 362; Gould, 1963, p. 47). 
búsqueda de la verdad. Por otra parte, si bien quien acrecentara su comprensión de la belleza y su amor por ella — hasta alcanzar quizá la contemplación de lo bello en sí- reconocería las limitaciones del amor carnal y de la hermosura física, esto a su vez lo habilitaría para justipreciar mejor, desde una perspectiva más amplia, el valor del cuerpo y así otorgar un sentido trascendente a su deseo sexual, a diferencia de quien permanece en un nivel meramente somático de amor y comprensión. En tal sentido, espero ofrecer una exégesis superadora y alternativa a la visión tradicional según la cual, aunque en algunos casos se reconoce que en ciertos discursos, como en el de Aristófanes ( $c f$. especialmente 192b5-c2) y el de Alcibíades (217a2-219d2), hay una valoración de la experiencia de enamoramiento y del amor "carnal-corporal", 9 se suele sostener que en los Misterios Mayores revelados por Diotima (209e5-212c3a) el modo correcto de conducirse y progresar en los asuntos eróticos para ascender hacia la Forma de la belleza implicaría el desprecio de los bellos cuerpos (210a9-b1; 210c5-6; 211d4-5) y, junto con ello, la cancelación del amor somático (Dover, 1982, ad 210c5-6; Reale, 2004, p. 220; Rowe, 1998, ad 210a6-7). Por último, me referiré al tipo de relación amorosa que establece el Sócrates platónico con jóvenes bellos, tales como Cármides, Lisis, Agatón y Alcibíades. Mostraré que en estos casos la expresión física de éros nunca es totalmente erradicada, sino que, por el contrario, se convierte en un punto de reconexión con la carencia constitutiva del deseo, el cual siempre es, no obstante, extensible a niveles eróticos más plenos y amplios.

\section{1. "Cuerpos amados" y "cuerpos amantes" en los discursos precedentes al de Sócrates}

Las cinco intervenciones en el Banquete previas a la de Sócrates/Diotima pueden entenderse como recreaciones de "concepciones notables" (éndoxa) de la época provenientes de distintos campos o disciplinas, ${ }^{10}$ con las cuales Platón compite al

9 Así para Nussbaum (2001, pp. 165-234) en los discursos de Aristófanes y Alcibíades habría una actitud positiva hacia el amor sexual, en oposición trágica, a su juicio, al amor abstracto e impersonal del discurso de Diotima. En este último punto coincidiría con Vlastos (1973, pp. 3-42) para quien el éros platónico en tanto amor por la Forma implica egoísmo y la utilización de la persona como mero medio que permite el ascenso al ámbito inteligible. La interpretación aquí propuesta se distancia de esta lectura en lo que se refiere a la valoración del amor físico, pues sostenemos que si bien el apego a los cuerpos bellos individuales y a la belleza física en general debe ser para Platón trascendido, la realización del amor en el conocimiento de la Forma de la Belleza permite un mejor aprecio de la hermosura sensible y, por otra parte, puede servirse de este plano como fuente de reconexión con la belleza inteligible.

10 Si nos remitimos a los dos sentidos de éndoxa que sistematiza Aristóteles en Tópicos I.1. 100a - lo que le parece bien a todos o a la mayoría; b) lo que le parece bien a los sabios, ya sea a la mayoría de 
tiempo que se apropia de sus registros discursivos (Nightingale, 1995, pp. 93-132), ${ }^{11}$ además de describir en estos discursos, desde distintas perspectivas (Soares, 2009, pp. 60-61) y bajo diversas máscaras (Reale, 2004), ${ }^{12}$ la naturaleza y bondades de Éros (Dorter, 1969). ${ }^{13}$ De modo más específico me interesa mostrar aquí cómo pueden detectarse en estos elogios a Éros, en un sentido dialéctico, ${ }^{14}$ indicaciones

ellos o a los más reputados - los elogios de los oradores del Banquete sobre el amor pertenecerían a la categoría b). En tal sentido Fedro representa, como en el diálogo homónimo (Phdr. 227e6-228c5a-c), a los admiradores de la retórica; Pausanias, a los sofistas (de hecho su distinción conceptual y lingüística de dos tipos de amores recuerda la preocupación de Pródico al respecto con quien se lo relaciona en Prt.315d1-316a2), y en especial a los erastai defensores de la institución pederástica; Erixímaco, a la medicina; Aristófanes, a la concepción popular del amor en la comedia (Dover, 1966, pp. 41-50); Agatón, a la tragedia, en tanto dramáticamente es su triunfo en este género en las Leneas del 416 a.C. el motivo de la fiesta (174a5-8, 194b1-8), si bien los aspectos estilísticos de su discurso evocan la oratoria sofística de Gorgias (198c3; Bury, 1932, pp. xxxv-xxxvi; Dover, 1980, pp. 123-124). Para mayores desarrollos al respecto vid. (Hunter, 2004, pp. 38-77; Scheffield, 2006, pp. 23-46).

11 Según este autor el Banquete cumple una función panfletaria y agonística, razón por la cual con los cinco primeros discursos del Banquete Platón ofrecería parodias de las distintas disciplinas que rivalizaban entonces por la hegemonía del saber a fin de presentar la filosofía, tal como él la entiende, como la campeona absoluta (Nightingale, 1995, pp. 13-21).

12 Soares (2009, pp. 60-61) sostiene que la perspectiva teórica de cada discurso encierra un núcleo parcial de verdad sobre la noción de éros, y no se puede sostener taxativamente una de ellas en desmedro de las otras, como se hace desde las posiciones exegéticas más tradicionales al respecto. En su clásico trabajo Reale (2004), por su parte, propone la interpretación del Banquete como un juego de máscaras en el que Platón con las cuatro primeras - los discursos de Fedro, Pausanias, Erixímaco y Aristófanesdescribe a Éros como no es; con la máscara del poeta trágico Agatón presenta el núcleo esencial sobre la naturaleza de Éros; con el complejo juego de tres máscaras - Sócrates, Diotima y nuevamente Agatón — revela la verdad sobre él como mediador entre lo sensible y lo inteligible — lo Bello, el Bien, lo Uno-, mientras con la de Alcibíades representa la irrupción del aspecto dionisíaco del amor.

13 La tesis central de Dorter (1969, pp. 215-234) es que, en tanto los discursos son "elogios" a Éros no solo pretenden establecer qué es sino, sobre todo, por qué es bueno. En tal sentido entiende que cada discurso corrige el precedente, en creciente orden de calidad, para culminar en el de Sócrates/Diotima que constituye así una especie de refutación de estos.

14 Asumimos aquí que "dialéctica" es para Platón, en sentido amplio, el arte de comprender y expresar correctamente lo que es (Dixsaut, 2001, p. 9) y, en sentido más específico, "el método ideal" para lograr dicha comprensión de lo real (Robinson, 1953, p. 66). Se suelen diferenciar dos versiones básicas del "método dialéctico": a) la deducción de una explicación de la realidad a partir de un principio único, en diálogos de madurez como República y Banquete - de la cual habría un anticipo en el método "a través de hipótesis" del Fedón-; b) la "reunión y división" en géneros y clases a fin reflejar la efectiva estructura de un aspecto de la realidad (vid. Hackforth, 1952, pp. 134-137). No obstante, como apunta Dixsaut (2001, pp. 7-12; vid. también Robinson, 1953, pp. 69-75), el "conversar o argumentar" — dialégesthai - en la filosofía platónica, sin nunca apartarse de su objetivo de alcanzar la verdad, adopta formas diversas según el contexto de investigación. En tal sentido, también en el caso del interrogatorio socrático típico de los llamados "diálogos tempranos" su objetivo no es simplemente sacar a la luz contradicciones ocultas en el marco doxástico del interlocutor de turno (vid. Robinson, 1953, pp. 7-49), así incentivarlo a continuar el examen de sus creencias y eventualmente a alcanzar 
de que el amor físico es bueno, siempre y cuando adopte la configuración apropiada y/o nos dirija a objetivos que lo trasciendan.

En tal sentido en su parlamento (178a6-180b8), Fedro, "padre del discurso" (177d5), admirador de oradores y sofistas ( $c f$. también Prt. 315c3) — y en el diálogo homónimo especialmente de Lisias-, si bien alude con el término Éros a la fuerza cósmica y generatriz de los grandes poetas (178b2-11; cf. Hesíodo, Teog. 116 y ss; Parménides 28 B 13), defiende como tesis central y provocativa que la intensa pasión sexual del amante por el amado constituye una fuerza motivadora fundamental para el engrandecimiento moral (178c1-d1). ${ }^{15}$ Celebra así en su encomio la capacidad de Éros de procurar los más grandes bienes para nosotros en tanto es el vigor (ménos, 179b1) que mejor incita tanto en quienes lo experimentan como en quienes lo despiertan, la ejecución de las más grandes muestras de excelencia y la vergüenza por las acciones deshonrosas (178c1-179a8). Asimismo sus tremendos efectos benéficos alcanzan no solo a los individuos involucrados en una relación amorosa, en quienes inspira actos de prodigioso heroísmo - e.g. dar la vida por el amado, en el caso de Alcestis por Admeto (179b4-d1), o por el amante, en el de Aquiles al vengar la muerte de Patroclo (179e1-180b5) - , sino que pueden repercutir incluso a nivel

una formulación consistente de estas (vid. Vlastos, 1983, pp. 28-57); tiene, además, como intención fundamental aproximarlo a una mejor comprensión de la naturaleza efectiva del objeto en cuestión (Penner, 2007, pp. 3-19). La manera en que se opera en Banquete con las opiniones reputadas que representan los cinco discursos previos al de Sócrates podría entonces entenderse, mutatis mutandis, de modo similar al élenchos socrático de los diálogos platónicos: estos constituyen un punto de partida para comprender y poner en diálogo distintas perspectivas sobre qué es éros, a la vez que estas son reconsideradas y superadas en el discurso de Sócrates/Diotima, en el que se nos revela más acabadamente la verdadera naturaleza del amor; en la medida en que la plena realización de éros se alcanzaría, según consta en allí, en el "ascenso erótico" a través del acceso a lo bello en sí como fundamento último ontológico y gnoseológico, la última etapa de la explicación de Sócrates/Diotima incluiría, además, el método dialéctico en su versión más específica a). En su concepto de dialéctica Aristóteles conserva el aspecto crítico de la dialéctica socrática pero lo entiende como un arte de discusión, auxiliar de la ciencia e independiente del conocimiento de un objeto determinado; a través de él se señalan las dificultades que encierran desde un punto de vista formal las opiniones de los sabios, las cuales representan las principales teorías en curso sobre el tema a abordar y, como propuesta metodológica, constituye para Aristóteles una superación de la versión b) del método dialéctico platónico (Moreau, 1962, pp. 43-46). Sobre el élenchos en el Banquete vid. Fierro (2015b, pp. 93-108).

15 Leemos así en 179a: “¡Nadie existe tan perverso que el amor no lo haga un inspirado respecto de la virtud!" En tal sentido Sheffield (2006), p. 17) comenta: "El discurso de Fedro es una explicación que incita a la reflexión de cómo éros puede conducir a la virtud" (Traducción de la autora). Asimismo, en su apología del aporte del, en general, poco apreciado discurso de Fedro en el Banquete, afirma Wardy (2012, p. 133): "Éros instiga al bello comportamiento; tò kalón es evidente de por sí como paradigma a ser emulado por los actores del caso y, además, como un portento a ser admirado por los espectadores" (Traducción de la autora). 
político, tal como en las posibles acciones de extraordinario arrojo en el campo de batalla, en caso de conformarse un ejército de amantes o amados (178e3-179b3).

En su discurso (180c2-185c3) Pausanias, representante del típico erastés adulto de su tiempo ( $c f$. también Prt. 315d6-e1), propone una distinción ausente en el elogio de Fedro, entre una forma innoble (aischrôs) y otra noble de amar (kalôs erân, 181a6): el Éros vulgar — heterosexual y/o homosexual (181a1-c2)— de la Afrodita Pandemo, en tanto es meramente físico - "ama más al cuerpo que al alma" (ho toû sómatos mâllon ê tês psychês erôn) (181b4)—, ${ }^{16}$ es descalificado como ruinoso tanto para el amante maduro como para el jovencito y debería ser sancionado según apropiadas normas ( 181e3-182b6); en cambio, el amor de la Afrodita Urania, "celeste" y exclusivamente homoerótico, en tanto no busca solo concretar la unión sexual con el amado sino también su mejoramiento moral de acuerdo a normas apropiadas para la conducta de ambos, es enaltecido. ${ }^{17}$ No obstante, en este segundo caso, si bien orientado hacia una acción noble (praxis kalé, 180e4-5), Éros no deja de ser concebido primariamente como la atracción física del amante por el bello joven ni renuncia tampoco a la satisfacción de la unión corporal. ${ }^{18}$ Por el contrario

16 En su clásico trabajo sobre la psicología platónica Robinson señala, a través del estudio de distintos diálogos —entre los que no figura centralmente el Banquete-, que Platón utiliza el término psyché de manera ambigua y multívoca, atribuyéndole entre otros sentidos por ejemplo en uno de los diálogos más representativos al respecto —el Fedón —, el de "principio cognitivo de lo inteligible", "principio vital", "persona interior" o "yo", "estado ontológico intermedio/intermediario", "fluido vital" (Robinson, 1995, pp. 21-33). Entendemos que en Banquete "alma" es utilizado, en cambio, de un modo más general en referencia al centro de las actividades mentales-emocionales-morales, tal como se expresa luego en 207e1-5 (vid. n. 35 infra). Es el Éros metaxý - “intermedio/intermediario"- entre lo mortal y lo inmortal, descripto en el Discurso de Sócrates/Diotima y conducente en último término a la contemplación de lo bello en sí, el que cumple aquí un rol análogo al alma en Fedón (cf. Eggers Lan, 1983, pp. 54-55).

17 Peixoto (2012, pp. 167-168) sintetiza así las diferencias entre los dos tipos de amor en el discurso de Pausanias: el "amor vulgar" es sobre todo por el cuerpo, dirigido a individuos necios y a la concreción inmediata de su deseo, sea bueno o no, y es efímero; el "amor celeste", en cambio, ama lo más valioso y dotado de inteligencia, se enamora de quien tiene carácter noble y es constante porque se apega a algo permanente, el alma del amado. En tal sentido esta autora supone que el elogio pausánico anticipa a través de la discriminación de dos tipos de amores la distinción del discurso de Diotima entre lo que es visible y nace y perece, y lo invisible — la Forma de la belleza - que siempre es.

18 Leemos entonces en 184d3-e4: "Pues, cuando amante y amado, cada uno con su norma, se dirigen al mismo objetivo (uno asistiendo al complaciente jovencito (charisaménois paidikoîs) como es justo, el otro, sirviendo (hypourgôn) al que lo hace sabio y bueno como es justo; uno siendo capaz de contribuir en sapiencia y otras virtudes, el otro precisado de poseer recursos para su educación y otro tipo de conocimientos [...]), ocurre que es bello complacer (charísasthai) al amante". El conceder los favores sexuales por parte del jovencito era designado, eufemísticamente, en griego con el verbo charizeisthai — "hacer un favor"- y a veces hupourgeîn - "hacer un servicio", este último término tomado del lenguaje militar. 
el panegírico de Pausanias está justamente dirigido, cínicamente o no (Neumann, 1964, pp. 261-267), ${ }^{19}$ a justificar la legitimidad y nobleza de la gratificación sexual en el caso del "amor celeste".

Como ha señalado Holmes (2010, pp. 13-14; 162-170), las formulaciones en los tratados médicos constituyen un hito fundamental en la cultura griega para el surgimiento de las conceptualizaciones respecto del cuerpo. ${ }^{20}$ En tal sentido la exhibición discursiva de Erixímaco (185e6-188e4) se centra principalmente en el éros en relación con los cuerpos y en el modo en que este opera no solo en la esfera humana - la referencia a la sexualidad humana es de hecho casi nula (Rowe, 1998, p. 147; 1999, pp. 53-64) - sino también en los cuerpos de los animales, en todo lo que crece sobre la Tierra, y, en general, en todos los seres (186a3-7). Así la medicina es definida como "el conocimiento de los procesos corporales eróticos que redundan en repleciones y evacuaciones" (186c5-7). Su ámbito de incumbencia se emparenta entonces con el de la gimnasia, la agricultura (187a1), la música (187a1e8), y en general con todos los campos profesionales humanos y divinos (187e6-8; 186b1-2); en el caso de los temas divinos estos consistirían en el conocimiento del ritmo de la naturaleza, del movimiento de los astros (188a1-b6) e incluso en la mántica como arte de comunicación entre dioses y hombres (188b6-d3). Con la intervención de Erixímaco se retoma y se reformula así dialécticamente, desde una nueva óptica, la distinción pausánica de una doble naturaleza de Éros (186a1-2) de modo que: a) el amor excesivo y dañino, productor de enfermedades y descalabros de todo tipo, es negativo y debe ser extirpado; b) el amor moderado y saludable, que la medicina ${ }^{21}$ intenta promover y restablecer a través de la armonización de los opuestos (186d6-7), es considerado benéfico. Vemos entonces que en este discurso el Éros corporal per se no es rechazado sino, por el contrario, valorado, siempre y cuando reciba un tratamiento conveniente el cual supone que se favorezca a los apetitos del cuerpo que son saludables y se inhiba a aquellos que enferman (186b8-

19 Este autor sintetiza distintas posiciones exegéticas respecto a si el verdadero propósito de este discurso es o no defender la mera obtención de los favores sexuales del jovencito, mientras que por su parte se propone mostrar que "ninguna aspiración más elevada se debe atribuir a Pausanias" (Neumann, 1964, p. 261; traducción de autora). En trabajos recientes como el de Renaud (2016, pp. 140-145) se retoma la hipótesis de que la virtud y la educación son el vector principal de la exposición de Pausanias, quien aceptaría e incluiría la sexualidad en la relación "amante-amado" pero en un rol secundario y menor.

20 Además de los tratados hipocráticos, Platón también utiliza en su construcción de la alocución de Erixímaco otras teorías físicas, principalmente las de Empédocles y Heráclito, que adapta, no obstante, a sus objetivos filosóficos (vid. Parry, 2016, pp. 160-164; Candiotto, 2015, pp. 81-93).

21 Candiotto (2015, pp. 81-93) muestra cómo la "téchne armónica" apunta a un ordenamiento cósmico que anticipa en gran medida planteamientos ético-cosmológicos de diálogos como Timeo. 
c5). Es por ello que autores como Stalley (2016, pp. 167-168) sugieren que la noción de "amor saludable" de Erixímaco se aproxima a la concepción popular de autocontrol - sophrosýne-, entendida esta como restricción de los apetitos que causan dolor o impiden el placer. No obstante, no se trataría de una teoría del deseo que trascienda el nivel físico (Parry, 2016, p. 164) ${ }^{22}$ y, en tal sentido, como reconoce el propio Stalley, tampoco se distinguiría de modo explícito en este discurso entre lo que es bueno para el alma y lo que es bueno para el cuerpo, y asimismo entre el placer y el bien, como sí ocurre, por ejemplo, en Grg. 464b2-466a3 (Stalley, 2016, pp. 167-168).

E1 fantástico mito de Aristófanes (189c2-193e2), como ya señalara Nussbaum (2001, pp. 165-199), ${ }^{23}$ ofrece una mirada positiva del deseo sexual, de los cuerpos "amados-amantes" que se buscan mutuamente. Tras el cercenamiento de los primeros humanos como castigo a su desenfreno — akolasía, 189e 8 - y la adquisición por parte de estos de un cuerpo "monstruoso" en relación con aquel originario de forma circular (189e5-190a4; von Möllendorf, 2009, pp. 94-97), ${ }^{24}$ los dioses reubican frontalmente los genitales en los seres humanos. De este modo hacen posible el coito entre dos mitades a fin de aliviar, en un encuentro casual y momentáneo, el anhelo por la unidad perdida, y facilitar así la prosecución normal de la vida, sin que cada mitad perezca en un abrazo eterno con el amado (191a5b1). Por otra parte, cuando el mismo impulso - Éros - hace que alguien se tope con su mitad original y entonces se enamore, se revela a los enamorados algo de otra índole, inefable, que trasciende la unión carnal y que estos son incapaces de describir. Este anhelo solo encuentra expresión enigmática (manteúetai, 192d1) en el ansia de fundirse el uno con el otro para siempre (192d2-e9), es decir en la fantasía - imposible de concretar en nuestra condición humana actual— de una interpenetración absoluta de un cuerpo y otro en el acto sexual (von Möllendorf 2009, pp. 91-94). El cuerpo del amado al que nos unimos es aquí de vital importancia en tanto opera como una "contraseña" — sýmbolon, 191d5- de esa completitud

22 Parry (2016, p. 164) sostiene que la gran limitación del discurso de Erixímaco es que se restringe al tratamiento de cómo moderar mejor los apetitos corporales, los cuales, dada la naturaleza cambiante e inestable de su objeto, siempre son fuente de desequilibrio.

23 A diferencia de la interpretación aquí propuesta, esta visión de Aristófanes contradice a la que se presenta en el Discurso de Sócrates/Diotima. Para ella recién en el Fedro (Nussbaum, 2001, pp. 200-234) Platón haría un viraje y valoraría el amor carnal por un individuo en particular.

24 Este autor interpreta que en el discurso de Aristófanes nuestra configuración corporal actual es descripta como "monstruosa" de acuerdo al sentido original de théras —en latín monstrum —: algo grandioso y terrible, enviado por los dioses y demandante de explicación. 
añorada; asimismo el que ama halla en su cuerpo, a través de los pliegues del ombligo, un recordatorio (mnemeîon, 191a4) que lo remite a aquella amputación primigenia, a esa falta constitutiva. El amor carnal, sobre todo en el enamoramiento, es aquí, pues, valorizado en tanto es anhelo por la unión sexual que, a su vez, apunta a algo que la trasciende: la recuperación de esa plenitud arcaica y perdida. ${ }^{25} \mathrm{Y}$ es en este sentido que Aristófanes demuestra, como propuso al comienzo de su discurso, que Éros es el "más filantrópico de los dioses, el protector de la humanidad y el sanador de todos los males cuya cura traería felicidad generalizada a toda la raza humana" (189c8-d3).

El panegírico de Agatón a Éros consiste fundamentalmente, como a menudo se ha señalado, en una alabanza al amado e indirectamente a Agatón mismo. ${ }^{26} \mathrm{En}$ tal sentido vincula la máxima dicha de este dios con su extrema belleza y bondad (kálliston kaì áriston, 195a7). ${ }^{27}$ En cuanto a su hermosura, la celebra cual lo haría el enamorado de un joven mancebo al enumerar sus atributos físicos y exaltar entonces su lozana juventud (195a8-c7), su delicadeza (195c7-196a1), la atrayente fluidez de sus movimientos (196a1-6), la perfecta simetría de sus rasgos (196a46), el esplendor de las flores y los perfumes deliciosos como su hábitat natural (196a7b3). Tras asignar al Amor estas cualidades relacionadas primordialmente con la apariencia corporal, Agatón demuestra a continuación que Éros es, además, excelente. Desencadena entonces la atribución a este de la habitual constelación de las virtudes cardinales: la justicia, la moderación, la valentía y la sabiduría

25 Esto sería básicamente la inmortalidad — expresado en la historia de Aristófanes en el deseo de los amantes de estar unidos para siempre en el Hades (192e)—. Afirma así al respecto Scolnicov (2016, p. 180): "Los hombres de Aristófanes anhelan algo que no saben qué es y que no pueden alcanzar. [...] El hombre quiere trascender esta vida pero difícilmente puede ir más allá de imaginarla como una especie de extensión de esta vida empírica" (traducción de la autora).

26 "Una de las principales características del discurso es el grado en que se refiere al propio orador, no solo a través de la descripción del Amor como poeta y hacedor de poetas [...] sino también, sin lugar a dudas, a través del énfasis en la belleza juvenil del Amor" (Rowe, 1998, ad 194e4-197e8; traducción de la autora). Recientemente este punto ha sido desarollado por Regali (2016, pp. 204-208). La comedia aristofánica Tesmoforiantes en los versos 191-192 brinda un testimonio, si bien de tonos paródicos, de la representación de Agatón en el imaginario social de la época, a saber la de un hombre "de bello rostro (euprósopos), blanco (leukós), afeitado (euxyreménos), voz afeminada (gynaikóphonos), suave (apalós), y apuesto (euprepés)" (vid. también Hunter, 2004, p. 75). Platón también refiere a Agatón en Prt. 315d8-1 como un adolescente "de natural noble y muy bella apostura" (kagathón tèn phýsin, tèn d'oûn idéan pánu kalós).

27 Asimismo afirma Agatón en 197c1-2: "El Amor, en sí mismo siendo primero que nada bellísimo y excelente (prôtos ... kállistos kaì áristos).” En 197e2-4: “el más bello y excelente (kállistos kaì áristos) guía al que debe todo hombre seguir". 
(196c1-e2), esta última íntimamente ligada aquí a la poesía — profesión de este orador - como conocimiento clave para acceder a otras artes (196e2-197b7). La belleza corporal y la belleza moral de Éros van, pues, de la mano en el abordaje propuesto en este encomio. ${ }^{28}$

Así pues, desde distintos enfoques, todos los discursos previos al de Sócrates valorizan el amor carnal, si bien este aprecio aparece sujeto a ciertos condicionamientos ético-epistémicos, o al menos proyectado a la apertura de la existencia humana a un plano que supera el nivel puramente físico.

\section{2. "Cuerpos amados" $\mathrm{y}$ "cuerpos amantes" en el discurso de Sócrates/Diotima}

Los puntos de vista conflictivos respecto al cuerpo y su importancia parecen prima facie intensificarse cuando llega el turno de la exposición de Sócrates a través de la máscara de Diotima, en la cual suele considerarse que se expresa la posición más propiamente platónica (vid. aquí notas 10-13 supra). En efecto, por una parte, en los Misterios Mayores ${ }^{29}$ (209e5-212c3) el progreso en los asuntos eróticos, implica como primer paso: el desprecio de los bellos cuerpos para poder empezar el ascenso hacia la Belleza (210a9-b1); la consideración de la belleza del cuerpo como algo "fútil" (smikrón ti) comparado con la belleza del alma (210c5); el desapego del cuerpo en el mayor grado posible para alcanzar el conocimiento de lo bello en sí (211d3-8). ${ }^{30}$ La única razón valedera para que el verdadero amante - esto es, el filósofo- ame los cuerpos bellos es que sean un medio para acceder a la realidad eidética, identificada aquí con la Forma de la belleza (Dover, 1982, ad 210c5-6; Reale, 2004, p. 220; Rowe, 1998, ad 210a6-7). Por otro lado, hay sin embargo otros aspectos relevados en la primera sección del Discurso de Sócrates/Diotima,

28 Ya en Homero los héroes son calificados como kalokagathós y de este adjetivo se deriva luego la expresión kalo kagathía que designa la suprema virtud del hombre. Vid. Jaeger (1957, pp. 22-32).

29 Los ritos iniciáticos de las religiones mistéricas, particularmente los de los Misterios de Eleusis, son reinterpretados aquí en clave platónica. Así mientras que los Misterios Menores están abiertos a un público amplio, para los Mayores se requiere "ser iniciado" y contemplar en algún grado las Formas, ya sea en nuestro modo de vida actual o después de la muerte. Sobre este punto vid. Peixoto (2012, pp. 170-171); Rowe (1998, ad 210a6-7).

30 Se reiteraría entonces en Banquete el desprecio por el cuerpo típico del Fedón (Phd. 66b1-67b5), si bien allí el contexto dramático luctuoso de la inminente muerte de Sócrates vuelve más apropiada una consideración negativa al cuerpo, sometido como todo lo sensible al cambio y en este caso a su próxima y absoluta corrupción. 
denominados "Misterios menores" en contraposición a la subsiguiente (209e5-6), que sugieren fuertemente una mirada positiva respecto del amor físico $\mathrm{y}$, junto con él, del cuerpo. En el discurso de Sócrates/Diotima, aunque el deseo que emerge de un cuerpo y busca mera satisfacción sexual es considerado una forma inferior de amor (209c7-d1), es no obstante visto como algo beneficioso. En efecto la expresión básica de éros a través de la procreación biológica es presentada como una fuerza vital positiva (206c1-207e1), puesto que el deseo sexual de copulación y reproducción que compartimos con los animales es parte de un deseo general hacia la inmortalidad y la posesión permanente del bien, que, en el caso de los mortales, solo puede lograrse a través de una procreación y sustitución permanente del objeto de amor (206e5-207b4; Ostenfeld, 1982, p. 207; Rowe, 1998, ad 207a5-208b6).

Lo que me propongo mostrar a continuación es que, tal como se preludia en los encomios a Éros precedentes, estos puntos de vista aparentemente conflictivos sobre el cuerpo en el Discurso de Sócrates/Diotima del Banquete no son contradictorios sino complementarios, fundamentalmente por dos razones:

a) El cuerpo es esencial para que se detone el éros ya que la atracción sexual hacia los cuerpos bellos es el modo más natural de que se inicie en alguien la experiencia erótica. Por lo tanto, debe ser valorado porque es el primer paso necesario para que comience el desarrollo de éros.

b) El ascenso a lo bello en sí implica un desapego de los cuerpos particulares a fin de alcanzar una apreciación más amplia y general. Pero, a su vez, si se logra esta mirada más abarcadora, esto permite una mejor valoración de todas las instanciaciones de belleza, incluidas las corporales, al tiempo que nos permite expandir nuestra condición erótica más allá del nivel físico.

\section{1. “Cuerpos amados" $y$ "cuerpos amantes" en los Misterios Menores (201d1-209e5)}

En 207d8-e1 el cuerpo es considerado como un conjunto de componentes biológicos, tales como pelo, carne, huesos y sangre. ${ }^{31}$ No obstante, el cuerpo no es por eso

31 "Hábitos, rasgos, opiniones, deseos, placeres, penas, miedos y porciones de conocimiento" son, en cambio, atribuidos al alma (207e1-208a6). En el Fedón se desarrolla, en cambio, una concepción más compleja del cuerpo. Por ser este la dimensión antropológica más semejante a lo sensible (Phd. 79b4-6, 16-17; 80b3-5), a través de él tienen lugar la sensopercepción y la búsqueda del placer sensible ( $P h d$. 64d9-65b8). No obstante, se originan a partir de él, además de deseos claramente identificables con 
un fárrago de estos distintos aspectos, sino que estos componentes se dice que están sometidos a un constante flujo y renovación gracias a la acción constante y reparadora de éros. Así que, incluso en este nivel básico, el cuerpo viviente no es una materia inerte de partes anexadas sino un "cuerpo amante", es decir impregnado de éros que actúa como una fuerza unificadora, vivificante y restauradora.

El inicio de la descripción de las acciones - érga- del amor con la "procreación en lo bello según el cuerpo" — tókos en kaloî katà tò sôma (206b78) - también sugiere que el impulso erótico por la inmortalidad tiene su comienzo natural a nivel somático. Recordemos que como éros es por naturaleza un híbridointermediario, un (metaxý), que combina la carencia de origen materno con el ingenio paterno (202d1-204c6), la posesión de su objeto de deseo, que es lo verdaderamente bueno junto con la inmortalidad como condición concomitante (204d1-206a13), le está vedada, por lo cual solo le queda reproducir y sustituir permanentemente su objeto en cuestión (208a7-b4). Este proceso tiene lugar en primer término justamente, en todos los animales incluido el hombre, a través de la procreación biológica en lo bello y el cuidado de la prole (207a5-c1). Es por eso que la unión sexual entre el hombre y la mujer es considerada "algo divino" (theîon tò prâgma, 206c6). Es cierto que uno de los propósitos de Sócrates/Diotima en Banquete es la

necesidades fisiológicas como el hambre, los cuales emergen de desequilibrios netamente corpóreos, otros fenómenos mentales. Leemos así en Phd. 66b7-c4 (las cursivas son mías): "En efecto, el cuerpo nos proporciona (hemîn paréchei) múltiples distracciones debido a la necesidad de alimento [...]. Por otra parte, nos colma (empímplesin hemâs) de amores, apetitos, temores, de toda clase de representaciones ilusorias y de muchas tonterías [...]." (Nótese que el cuerpo y sus apetencias dan origen también al deseo de posesión de riqueza y, con este, a la guerra; $P$ hd. 66c5-d2). Estos diversos fenómenos mentales pueden ser atribuidos al alma, a pesar de ser descripta allí esencialmente como simple, racional y pura (en semejanza a lo inteligible; Phd. 79b7-17; 80b1-3), en tanto emergentes de la contaminación que conlleva su convivencia con el cuerpo ( $c f$. Phd. 65c4-d3). Pero también puede pensarse que, de algún modo, corresponden al cuerpo, junto con su materialidad sensible, puesto que por él se generan. En cambio en la teoría psicológica de República (435a4-441e6) — y de modo similar en Phaedr. 246a3b4; 253c7-254e8 este tipo de fenómenos mentales se encuentran claramente distribuidos entre la parte apetitiva y la parte irascible del alma, y diferenciados de la parte racional. Así Gallop (1975, p. 89) sostiene que "Los fenómenos considerados en esos diálogos como un 'conflicto mental' son descriptos en el Fedón como combates entre el alma y el cuerpo: el alma se opone a las 'sensaciones del cuerpo' (94b7-c1; c9-e6), las cuales incluyen no solo el hambre y la sed (94b8-10) sino también las pasiones y los temores (94d5)" [traducción de la autora]. Esto ha llevado a intérpretes como Eggers Lan (1983, pp. 53-54) y Poratti (1993, pp. 72-73, n. 47) a afirmar que el cuerpo representa en el Fedón nuestra existencia de facto y el alma el sentido que el lógos imprime a dicha facticidad. Sobre la multiplicidad de sentidos de "alma" en el Fedón y su relación con el éros-metaxý en el Banquete ver n. supra. Sobre cómo el tema puede funcionar como obstáculo pero también como vehículo de alma vid. Fierro (2013b, pp. 7-42); también Ostenfeld (1987). 
expansión de éros, mostrando que no se reduce a la atracción sexual por alguien, sino que es el deseo que guía y constituye la vida de cada persona (205a5-d8). Y, de hecho, uno de los puntos principales de los Misterios Menores es mostrar que, en el caso del ser humano, éros se puede transformar y pasar de ser un puro deseo físico a una procreación cultural en la belleza, esto es las bellas producciones "según el alma" cuya mayor permanencia aseguran, por lo tanto, un mayor grado de inmortalidad a través de la generación en lo bello (Peixoto, 2012, p. 169). Sin embargo, para que el motor del deseo se encienda es necesario el éros "según el cuerpo"; es a partir de esta experiencia —y del lenguaje que la describe — ${ }^{32}$ que se construye la creatividad artístico-intelectual en general y filosófica en particular.

Además, es evidente que el modo más espontáneo de que se despierte el éros en alguien es a través de un cuerpo deseable, que constituye asimismo el medio más apropiado para procrear, tal como se sugiere en 206d3-7:

...cada vez que lo que está preñado se aproxima a lo bello, se alegra, se derrama con gozo, y da a luz y procrea, mientras que cuando se aproxima a lo feo, se contrae, encerrándose con pena, se aleja, se encoge y no procrea.

No obstante, si bien cualquiera puede tener la experiencia de tener un "cuerpo amante", en el caso de los cuerpos "amables" estos deben cumplir con el requisito de ser bellos. Pues es gracias a la belleza ${ }^{33}$ que adquieren un estatus especial que hace que resalten entre los restantes cuerpos. Ahora bien, a pesar de que el texto sugiere que es mejor reorientar el amor hacia las bellas almas a fin de procrear "según el alma", ${ }^{34}$ esto no cancela que siga operando la atracción por los bellos

32 Según Dover (1980, p. 147) los términos empleados en esta sección del Banquete para referirse a la procreación - los verbos tíktein, gennân y los correspondientes sustantivos tókos y génesis - refieren tanto a la "concepción" de un hijo como al hecho de "tener un hijo" en general, mientras que kyeîn — "estar embarazada" - y kýesai - "concebir" serían utilizados exclusivamente en referencia a las mujeres. Para Dover tíktein, junto con tókos, refiere a la eyaculación del semen por el hombre y probablemente a la emisión de algo similar al semen por parte de la mujer en el momento del orgasmo, y no al proceso de procreación de un niño que es lo que llamaríamos normalmente "embarazo". Pender (1992, pp. 72-86) ha mostrado, no obstante, que el discurso de Diotima haría referencia a cuatro tipos de "embarazo": dos físicos —el estado de embarazada de la mujer después de la relación sexual; la eyaculación masculina en el acto sexual-y dos espirituales que son metáforas construidas a partir de los dos tipos de "embarazo" físico. Brisson (1998, p. 65), por su parte, piensa que "a una concepción masculina de la educación asociada a la eyaculación, Diotima opone una concepción femenina como procreación" (traducción de la autora).

33 Cf. Phdr. 250d1-3; Nightingale (2004, pp. 39-186).

34 La procreación "según el alma" consiste, en primer término, en la reproducción de todo aquello que, según mencionamos en n.35 supra, la constituye, especialmente en la renovación y conservación de los conocimientos a través de la revisión continua de estos (208a3-7); en segundo término, en las obras 
cuerpos, y de hecho se afirma en 209b4-7 que si se puede dar la combinatoria de un cuerpo bello con un alma bella, mejor todavía:

Así que va detrás de cuerpos bellos más que de cuerpos feos, ya que está preñado; y si encuentra un alma que es bella, noble, y bien dotada, se complace en verdad por la combinación "cuerpo bello-alma bella".

Vemos, pues, que en los Misterios Menores el cuerpo es presentado como algo positivo en tanto que la forma de expresión primera de éros es a través de un cuerpo amante y por un cuerpo bello y amable, si bien se propugna que éros se expanda hacia formas de procreación más sutiles, tal como es la fecundidad cultural.

\subsection{Cuerpos amantes y cuerpos amables en los Misterios Mayores (209e5-212c3)}

En la sección correspondiente a los Misterios Mayores, Diotima proporciona indicios sobre un sendero más difícil pero, por otra parte, mucho más enriquecedor y pleno para acercarse a tà erotiká, que conlleva un desarrollo pleno de éros como "amor a la verdad" o philo-sophía. En este itinerario la atracción hacia los bellos cuerpos constituye el primer paso natural: "Pues es preciso, dijo, que quien se dirija a estas cuestiones [i.e. las cuestiones eróticas] comience, siendo joven, por dirigirse a los bellos cuerpos (tà kalà sómata) (210a4-6).

El cuerpo es esencial para que se dispare el despliegue del erotismo por las mismas dos razones que veíamos en los Misterios Menores: los bellos cuerpos son el facilitador más eficaz, en primera instancia, para que surja el deseo erótico; asimismo, el deseo sexual es el modo primero en que alguien pueda comenzar el ascenso erótico hacia lo bello en sí a través de experimentarse a sí mismo como un amante que desea y quiere procrear. No obstante, como se sabe, incluso en este nivel, la persona iniciada ya debe comenzar a realizar un desenvolvimiento intelectual así como existencial que lo "eleve" más allá de la belleza de los cuerpos particulares. Leemos así en 210a6-b6:

Y, primero, si el guía guía de modo correcto, es preciso que él se enamore de un solo cuerpo (henòs...sómatos erân) y procree en él (entaûtha) ${ }^{35}$ bellos discursos (lógous kaloús). Y,

y creaciones culturales que de ella surgen y que, al permanecer en la memoria colectiva, proporcionan virtud y fama imperecederas a través de sus "criaturas", particularmente los poemas y las leyes (208c1209e4).

35 El adverbio entaûtha tiene básicamente dos sentidos: uno locativo — "allí"—y otro temporal 
después, que comprenda que la belleza que hay en cualquier cuerpo es hermana de la de cualquier otro cuerpo, y que, si es preciso perseguir lo bello en su forma específica, es gran insensatez no considerar la belleza en los cuerpos como una y la misma (hén te kai tautón ... pâsasi toîs sómasi kállos). Y, tras comprender esto, debe hacerse amante de todos los cuerpos (pánton tôn kalôn somáton) y apaciguar este amor intenso por uno solo, despreciándolo y considerándolo algo trivial (kataphronésata kaì smikrón hegesámenon).

¿En qué consistiría este primer estadio erótico en relación con los bellos cuerpos? Una interpretación posible de este enigmático pasaje — dentro del tono críptico y misterioso de todo el ascenso- podría ser la siguiente. Aunque la procreación de discursos no implica necesariamente que la procreación física deba ser erradicada, lo importante es que esta experiencia erótico-somática da justamente lugar a la producción de "discursos/argumentos". Ahora bien, ¿de qué se tratarían estos discursos? Un modo natural de entenderlos sería que refieran a las palabras que normalmente utiliza un amante para referirse a los atributos de su amado y/o para seducir a la persona de la que está enamorado. ${ }^{36} \mathrm{Si}$ así fuera, habría que entender que en el pasaje se incentiva al sexo promiscuo en tanto el amanteiniciado es incitado a que ame a todos los cuerpos bellos por igual. Sin embargo, estas mismas aserciones se pueden entender como un estímulo para comprender la belleza común a todos los cuerpos bellos y a una mejor apreciación de ellos al captar el patrón común que hace que todos ellos sean bellos. A partir de esta comprensión se generarían entonces otro tipo de bellos "discursos". Por otra parte, si bien los bellos cuerpos que despiertan el deseo erótico serían en primera instancia los cuerpos de los amados, podrían también referir a otras formas de belleza perceptible, tal como las bellas producciones artísticas, los hermosos paisajes de la naturaleza, y, en el contexto de la filosofía platónica, muy especialmente, los cuerpos celestes ${ }^{37}$

— "entonces"— (vid. LSJ u.v. entaûtha). En este pasaje varios traductores prefieren el primer sentido —así Di Benedetto (1986), "in esso"; Juliá (2004), "en él”; Rowe (1998), "there”-; no obstante, Brisson (1998) adopta "alors" y Robin (1938), "à cette occasion". Optamos por el primer sentido siguiendo la interpretación de Dover (1980, ad loc.), quien piensa que el significado de este término aquí debe ser "with it" o bien "in it" puesto que Platón mantendría la idea, ya expresada en 209b1-3, de la necesidad de un entorno bello para poder procrear, el cual en este caso sería el bello cuerpo del jovencito. Agradecemos las indicaciones del árbitro ciego que nos señaló la necesidad de revisar con más atención la traducción de este término en este pasaje, si bien adoptamos la solución contraria a la por él sugerida.

36 Como ocurre en $L y .204 \mathrm{c} 3-\mathrm{d} 9$ con Hipotales, quien ha ensordecido a sus amistades con sus interminables elogios del bello Lisis. Laserre (1944, pp. 169-178) señala la ambigüedad del género de los erotikoí lógoi, los cuales podían corresponder tanto a los parlamentos al amado, como a tratados sobre el amor (como aquí en el Banquete), o a preceptivas sobre cómo comportarse en una relación amorosa.

37 En Ti. 40a5-7 los cuerpos celestes son de hecho descriptos como alhajas que adornan el cielo. 
y el universo en su conjunto. ${ }^{38}$ En este estadio del ascenso erótico hacia lo bello en sí tendría entonces lugar una apreciación "estética" más amplia, como sugiere Robin (1951, p. xciii), ${ }^{39}$ y ocurriría una expansión de éros, en la cual se dejaría de dar valor a un cuerpo bello, al entender y apreciar qué es lo que hace que ese cuerpo bello sea bello.

En un segundo momento de la scala amoris, la belleza del alma es priorizada por sobre la belleza del cuerpo, tal como leemos en 210b6-c6:

Después de esto, es preciso que considere la belleza en las almas como más valiosa que la del cuerpo (tô en taîs psychaîs kállos timióteron... toû en toi sómati), de modo que, si alguien es adecuado en cuanto al alma, incluso si tuviera poca lozanía física, [esto] le es suficiente para amar, cuidar, procrear e ir a la búsqueda de discursos tales que hagan mejores a los jóvenes, a fin de que se vea obligado a contemplar lo bello en las costumbres y las normas, y a percibir que esto [i.e. lo bello] es todo congénito consigo mismo, y así considere que la belleza respecto del cuerpo es poca cosa (perì tò sôma kalón smikrón ti).

No obstante, esta apreciación más amplia no conlleva un desprecio del cuerpo en cuanto tal sino que puede ser interpretada como un proceso a través del cual se comprende y se experimenta que un cuerpo no es únicamente un cuerpo sino que todo cuerpo está dotado de un alma, y más aún, que el cuerpo es un instrumento para que el alma se exprese. ${ }^{40}$ Así, en tanto el amante comprenda que tanto él como su amado tiene un cuerpo insuflado por el alma, y lo ame en cuanto tal, va a procurar que tanto él como su amado lleguen a ser mejores seres humanos, es decir, va a buscar producir discursos que hagan que en él se encarnen las bellas normas de conducta y las leyes cuya belleza la persona iniciada ha comenzado a reconocer.

De todos modos, el estadio final del ascenso erótico, cuando se alcanzaría la contemplación de la belleza en sí, parece implicar, entre otras cosas, un total desapego de lo somático, en el que los ojos del entendimiento se vuelven plenamente hacia lo inteligible (Peixoto, 2012, pp. 159-179). Dado que lo bello en sí es bello sin restricciones o determinaciones de ningún tipo, mientras que todas las cosas

38 Cf. Ti. 33b4-7 respecto de la belleza perfecta del universo en su conjunto. De hecho los carros alados de los dioses en el Fedro podrían representar "cuerpos-vehículos" perfectos arrastrados por un Éros cósmico que los conduce en movimientos inteligentes y regulares a través del universo.

39 Casertano (1997, p. 306) lo expresa de este modo: “...destacaremos (...) el carácter inextirpable del cuerpo, el cual no es solo el cuerpo del hombre, sino la visibilidad de todo lo que es perceptible en nuestra condición de ser en el mundo..." (traducción de la autora).

40 El cuerpo puede ser "obstáculo" o "vehículo" en Fedro (vid. Broadie, 2001, pp. 295-308); Alc. 1, 129e1-12). 
bellas particulares lo son en relación con una forma relativa o restringida, la belleza en sí deja de lado cualquier tipo de instanciación cuando se accede a ella en su pureza. No admite, pues, realizaciones, entre otras, de tipo somático. Se afirma en tal sentido en 210e2-211a7:

\begin{abstract}
Quien haya sido conducido hasta este punto en las cuestiones eróticas, al contemplar en orden y correctamente las cosas bellas, y al aproximarse ahora al objetivo último de las cosas eróticas, captará repentinamente algo bello en su naturaleza - eso bello justamente, Sócrates, por la cual tuvieron lugar sus anteriores esfuerzos-: primero, ni se genera ni se destruye $[\ldots]$; ni, de nuevo, se le mostrará lo bello como una cara, o manos, o cualquier otra cosa de las que participa el cuerpo (oudè állo oudén hôn sôma metéchei); ni como un discurso o un conocimiento...
\end{abstract}

Esto se refuerza con la declaración subsiguiente de que lo bello en sí es "puro, limpio, sin mixturas, y no contaminado con cosas como la carne humana (sarkôn anthropinon), el color y otras muchas cosas mortales y fútiles (phluarías thnetês)" (211e2-3). Sin embargo, esto no conlleva necesariamente un desprecio por los cuerpos bellos ni tampoco por otras expresiones más elevadas, pero de todos modos limitadas, de belleza, como es el caso de las bellas costumbres y leyes, y las bellas ciencias. Sería realmente extraño si la contemplación de lo bello en sí, en caso de acaecer, nos volviera ciegos respecto de las cosas bellas que nos rodean. ${ }^{41}$ Por el contrario, seguramente implica que seríamos capaces de percatarnos de un modo más revelador de la presencia de la belleza en sus diferentes manifestaciones en diferentes niveles, incluido, desde ya, su más obvia manifestación en los bellos cuerpos. Además, la procreación de verdadera virtud que le es posible a quien alcanzara este último estadio conlleva que ha adquirido una condición erótica sólida que le permite promover la creación de bellos productos en todos los niveles de la realidad, incluido el físico. De modo que el objetivo principal de este pasaje sería incentivarnos a que no le demos valor a las instanciaciones de la belleza en tanto tales -incluidos los cuerpos bellos - sino que logremos una apreciación y valoración de ellos desde un punto de vista más universal. ${ }^{42}$ No obstante, resta

41 Una reflexión encontramos, mutatis mutandis, en Krishnamurti (2009, p. 37) desde la perspectiva de la filosofía vedántica: "Después de haber observado todos los colores, las formas de la tierra, de las colinas, de las rocas, [...] a partir de ahí, trasládense de lo externo a lo interno [...]. Han terminado de mirar las cosas exteriores y ahora, con lo ojos cerrados, pueden empezar a mirar lo que sucede adentro. [...] Cuando hacen esto, ¿saben lo que sucede? Se vuelven muy sensibles, muy atentos a las cosas externas e internas. Entonces descubrirán que lo externo es lo interno, descubrirán que el observador es lo observado".

42 Vid. Moravcsik (1971); también Casertano (1997, pp. 307-310). 
preguntarse si quien alcanzara la cúspide de la scala amoris ¿podría prescindir o desprenderse en términos absolutos de las contingencias del amor carnal?

\section{Los "cuerpos amados" y "cuerpos amantes" de Sócrates y los bellos jóvenes}

Ahora bien, la relación que establece Sócrates con hermosos jóvenes en otros diálogos y en el Banquete con Agatón y Alcibíades constituye una muestra de lo analizado en los otros discursos, especialmente en el de Sócrates/Diotima. En efecto, a menudo Sócrates pone de manifiesto su atracción por sus bellos cuerpos al tiempo que los seduce, si bien lo hace en pos del objetivo mayor de conducir la corriente de deseo propia y ajena hacia la búsqueda de la sabiduría. Asimismo, el modo en que Sócrates despliega la vinculación con ellos pone en evidencia que en el amor filosófico la expresión física de éros no está ausente sino que, dominada y reencauzada, opera como el desencadenante más inmediato y efectivo del deseo.

Una buena ilustración a través de la figura de Sócrates de esta compleja concepción del amor carnal la encontramos retratada en la escena descripta en el pasaje de Cármides 153d2-155e3 que puede descomponerse para su análisis en los siguientes episodios. i) Sócrates, de regreso de Potidea, inquiere a Critias respecto de los jóvenes que al presente se destacan por su sabiduría, por su belleza o por ambas cualidades (153d2-5). Aquí, pues, ya hallamos una primera evidencia de su interés por los atractivos físicos de estos, además de por sus atributos intelectuales. ii) Critias señala entonces a su primo Cármides como el más bello, a juicio de todos, al tiempo que el joven ingresa rodeado de sus admiradores. Ante esto Sócrates lo recuerda como un niño de prometedora hermosura y, además, manifiesta una indiscriminada estima por todos los adolescentes en la flor de la edad como bellos. No obstante, al avizorar a Cármides, expresa su admiración por su altura y belleza al tiempo que observa el revuelo alrededor de él de los enamorados maduros que lo acompañan e, incluso, de los jovencitos de su edad. Se intensifica entonces en esta sección la expresión de Sócrates acerca de su gusto por la belleza física de los jóvenes en general y del hermosísimo Cármides en particular (153d5-154c8). iii) Querofonte no hace sino enfatizar y ahondar, con el fervoroso asentimiento de los presentes, en los sobresalientes atributos físicos de Cármides: frente a la observación de Sócrates respecto de la belleza del rostro del joven, su amigo subraya la absoluta hermosura de su figura corporal (tò eîdos; 154d 5 ; 154e6) que quedaría al descubierto si el joven se desnudara. Sócrates afirma entonces que si es 
así, encontraría a Cármides sin duda irresistible, si bien agrega la condición de que para ello el joven debe poseer también una hermosa alma. Sócrates acepta entonces acercarse a Cármides con el propósito de conversar (dialégesthai 155a5-6; vid. n. 16 supra) con él y comprobar sus cualidades intelectuales, especialmente las filosóficas y poéticas, que sus amigos adjudican al joven (para ello simulará ser un médico que puede aliviar la jaqueca de Cármides). Esta sección nos muestra entonces que Sócrates, para generar en Cármides bellos discursos ha sido motivado por la belleza de su alma no menos que por la destacable e impactante hermosura de su cuerpo (154c8-155b7). iv) El incidente que se relata aquí es por demás sugerente respecto al tema que nos ocupa. Todos los presentes, Sócrates entre ellos, quieren sentarse cerca de Cármides, al punto de empujar a quienes ya han logrado ubicarse a su lado, e incluso hacer caer a aquellos que quedaron en las esquinas del banco. Pero es solo Sócrates, acompañado por Critias, quien finalmente desplaza al resto y consigue situarse junto a Cármides (155b8-c5). Vemos entonces que los objetivos intelectuales de Sócrates van de la mano con un claro deseo de máxima proximidad física con el bello joven. v) Cuando está por dar inicio a su habitual interrogatorio, Sócrates describe sin ambages su turbación extrema cuando finalmente ve bajo el manto la hermosísima figura corporal (tò eîdos; 154d5; 154e6) de Cármides. Encendido de pasión, además de confundido y falto de confianza, reconoce, además, estar a punto de perder el control de sí mismo y sentirse a la deriva en sus conocimientos sobre éros. Es en este estado de explícita excitación física que Sócrates logra de todos modos responder con dificultad a la pregunta de Cármides e inicia con él una indagación dialéctica. Y para ello Sócrates no ha negado ni censurado su deseo físico por Cármides sino que, en la medida que puede, lo domina a fin de conducir al joven de su preocupación por aliviar su jaqueca a una investigación nada menos que acerca de qué es el autocontrol — sophrosýne — y su posible identificación con el conocimiento (epistéme). Por otra parte, el indudable atractivo físico de Cármides es al menos una de las causas que, a todas vistas, ha incentivado a Sócrates a elegir al joven y acercarse. En cuanto a Cármides, si bien no demuestra deseo de intimidad sexual con Sócrates, como sí lo hará Alcibíades, sí se manifiesta seducido por él y lo distingue al preferirlo entre todos como interlocutor y permitirle máxima cercanía física en la reunión (155c5-e3). Vemos entonces que este pasaje del Cármides se coincide con lo que hemos señalado en las secciones anteriores respecto del Banquete: Sócrates manifiesta su inclinación erótica por los cuerpos bellos de todos los jóvenes y su admiración por la sobresaliente apostura de Cármides en particular, si bien estos sentimientos están condicionados en el último caso a que el joven posea, además, una bella alma a fin de engendrar en ella bellos discursos. Esta 
restricción no impide, sin embargo, que sea invadido por la ola de pasión cuando Cármides lo hiere con su mirada y, sobre todo, cuando descubre bajo el manto el resto de sus encantos físicos.

También en el Lisis, Sócrates da muestras de similar inclinación hacia los jóvenes bellos como es el caso del protagonista (Ly. 204b1-2), a pesar de que, gracias a su don divino sobre asuntos eróticos ( $L y$. 204b5-c2; cf. también 205e1-206c7), no festeja - como sí ha hecho el desdichado Hipotales - al envanecido jovencito ( $L y$. 204d1-205d45) sino que lo refuta ( $L y$. 207d1-211a1), rebajándolo y degradándolo (Ly. 210e2-5) a fin de conducirlo a una reflexión sobre el cariño — la philía —. ${ }^{43}$

Por otra parte, en el Banquete Sócrates, quien suele prestar poca atención a su aspecto, concurre no obstante acicalado a la fiesta del apuesto Agatón (174a39). Esto sugiere que, sin ser bello en su aspecto físico, desea al menos mostrarse agradable. Por otra parte, no desalienta la proximidad física mutua, ante la insistencia de su anfitrión de que se siente a su lado, si bien le advierte que ello no producirá un automático traspaso por contacto del conocimiento (175c7-d-e6). Sócrates aprovecha, no obstante, la cercanía con Agatón para introducirlo a un trabajo reflexivo a fin de alcanzar real conocimiento o, al menos, aproximarse a ello. Esto se evidencia particularmente en el élenchos que Sócrates establece con Agatón (199c3-201c9). Allí incentivará a este último a revisar las creencias sobre Éros expresadas en su discurso - principalmente que el Amor es bello y bueno (195a7) - a reconocer la incoherencia de estas y con ello la propia ignorancia, y a generar así en el poeta la falta y el deseo de conocimiento que permita el surgimiento de creencias verdaderas y fundamentadas acerca de la naturaleza del amor. Estas últimas las introduce, en primer término, a través del mismo diálogo refutatorio con Agatón y, a continuación, por medio de su conversación con la sacerdotisa Diotima.

En cuanto a Alcibíades, era seguramente vox populi que Sócrates estaba enamorado de él, ${ }^{44}$ y demostraba una fuerte atracción hacia el apuesto y carismático general ateniense (216d2-4), quien es retratado en el Banquete todavía gozando del favor y admiración de Atenas. ${ }^{45}$ Por otra parte, Sócrates, pese a su proverbial

43 Philía refiere en griego en general y claramente en el Lisis a todo tipo de "cariño" puesto que indica afecto no solo por los amigos — relacionado con su traducción más frecuente por "amistad"—, sino también por los parientes, como es el caso del padre o de la madre (cf. X., Hierón 3.7).

44 Así lo manifiesta el propio Sócrates en Grg. 481d3-4 cuando declara ante Calicles: "cada uno [de nosotros] ama a dos: yo a Alcibíades, hijo de Clinias, y a la filosofía; tú, al pueblo ateniense y al hijo de Pirilampes."

45 El Banquete retrata a Alcibíades en la fiesta de Agatón en el zenit de su popularidad, pues la celebración se sitúa dramáticamente en el 416 a.C. aproximadamente, es decir poco antes de la desventurada expedición 
fealdad, lo ha seducido, según confiesa Alcibíades, no solo intelectualmente sino que, además, ha despertado en él un deseo de proximidad física e incluso de intimidad sexual. ${ }^{46}$ Asimismo, según manifiesta al cierre de su discurso, el hijo de Fenareta ha empleado similar estrategia no solo con él sino también con Cármides, Eutidemo y muchísimos otros atractivos jóvenes: la de aproximarse como amante para luego instalarse como amado (221a8-b7; cf. también 217a7-b4). Ahora bien, Sócrates actúa de un modo extraño pues, a la vez que seduce incluso físicamente a Alcibíades, frustra los intentos de intimidad sexual por parte de este (217a2-218a7) $\mathrm{y}$, en pos de hacerlo reflexionar sobre el sentido de su vida, tanto en el Banquete como en el Alcibiades $I,{ }^{47}$ resquebraja su autoestima y lo refuta. Leemos así en $215 \mathrm{e} 1-216 \mathrm{~b} 5:^{48}$
Cuando escucho [las palabras de Sócrates], mi corazón se agita frenéticamente más que el de los coribantes, y se derraman mis lágrimas por el efecto de sus dichos y veo que a muchísimos otros les pasa lo mismo [...], pues me obliga a confesar que yo me descuido a mí mismo e intervengo en los asuntos de los atenienses [...]. Mas una vez que me voy de su lado, me rindo ante los honores que me tributa la multitud.

Así pues, como mostramos en el análisis de los otros discursos del Banquete, el comportamiento de Sócrates con los bellos jóvenes muestra que éros se enciende desde el cuerpo — cuerpo amante — y por un cuerpo — cuerpo amado —, aunque el filósofo — aquí Sócrates — impida la concreción de este anhelo a fin de reencauzarlo como deseo por la verdad. En esto consistiría la perfección del autocontrol -

\footnotetext{
a Sicilia incitada por el propio Alcibíades en el 415 a.C. La conversación inicial de Apolodoro con sus amigos, en cambio, en la cual se recuerdan esos sucesos se ubicaría varios años después, cuando Alcibíades ya había caído en desgracia frente a los ojos atenienses, tras urdir oscuras confabulaciones y traiciones, y quizá ya había incluso muerto asesinado en el 404 a.C.

46 La fealdad física de Sócrates es, pues, eclipsada por su belleza "interna" (218e), incluso a nivel de la atracción sexual. La ética platónica expresa en tal sentido una subversión de la concepción griega habitual de belleza señalada por Konstan (2012, pp. 133-148).

47 En la puesta en escena del Alcibiades I tiene lugar la seducción erótico-filosófica del personaje homónimo por parte de Sócrates, cuyo objetivo principal es que el joven logre el autoconocimiento, entendido allí como "cuidado de sí" (Alc. I 127e1-2).

48 La extraña conducta de Sócrates hacia atractivos jóvenes como Alcibíades es, pues, similar a su actitud en el élenchos (vid. Gill, 1990, p. 82; 1999, p. xv y n.11). Cf. 175c2-e6; 199c3-201c9 en relación con Agatón y 218b8-219d2, 216a-b respecto de Alcibíades. Pero la intención de Platón no es criticar el uso de este procedimiento por parte de Sócrates por corromper a los jóvenes más prometedores al conducirlos así al escepticismo (contra Reeve, 1992, pp. 89-114): el élenchos, tal como muestra el diálogo entre Sócrates y Agatón previo al discurso de Sócrates/Diotima (199c-201a), no es inhibitorio sino propedéutico para el ascenso a lo bello en sí.
} 
sophrosýne - y del dominio de sí — enkráteia - para el Sócrates platónico en lo que refiere a la pasión erótica: no en suprimir ni reprimir su dimensión carnal — puesto que en ella se experimenta de modo inmediato y patente la naturaleza carente de éros-, sino en dominar esa pasión, y en expandirla y encauzarla, tanto en sí mismo como en otros, hacia el conocimiento de lo bello en sí. ${ }^{49}$

El carácter revelador de esta conmoción física frente al amado, en la cual el filósofo enamorado revive en el encuentro con el joven hermoso los estremecimientos frente a la contemplación de la belleza, es expresada de modo elocuente en Phdr. 251a1-b1:

...el recién iniciado [...] cada vez que ve un rostro divino o una figura corporal (sómatos idéan $)^{50}$ que imita bien la belleza, al principio se estremece y algo de sus antiguas conmociones lo asalta. Después, al mirar al amado, lo venera como a un dios y, si no temiera la reputación de desmedida locura, le haría ofrendas al muchachito como a una efigie sagrada y a un dios. Y, al verlo, a propósito de este estremecimiento, un cambio se apodera de él, un sudor y temperatura desacostumbrados.

A partir de esta perspectiva bidimensional en la que se reconoce lo bello en sí en el bello amado es posible entonces que, tanto en el amante como en el amado, el éros físico se transforme en una experiencia de una búsqueda más trascendental - la aventura de ir en pos de la sabiduría - en la cual el cuerpo opera como nuestro iniciador y compañero.

\section{Conclusión}

A través del análisis de los primeros cinco elogios a Éros del Banquete, del discurso de Sócrates/Diotima y de la relación de Sócrates con los jóvenes bellos en este y en otros diálogos puede concluirse que el amor platónico no excluye su manifestación

49 En tal sentido entiendo que el "drama de sátiros" (Sheffield, 2001, pp. 193-209; 222d3) de Alcibíades con que culmina la pieza dramática del Banquete constituye una historia de amor personal (Nussbaum, 2001, pp. 165-199), pero de alguien que se ha enamorado de un extraño individuo como Sócrates, quien encarna el Éros-philósophos descripto por Diotima (Bury, 1932, p. 1x; Dover, 1980, p. 164; Rowe, 1998, p. 206) y se comporta por tanto, desde la perspectiva de Alcibíades, el "niño bonito" del momento, de manera inusual a la esperada (para una consideración reciente del tema vid. Boeri, 2016, pp. 362-370), especialmente al negarle la gratificación sexual.

50 Aquí no la Forma o Idea metafísica sino idéa en la acepción más amplia de "estructura, figura". Vid. LSJ u.v. idéa. 
carnal — sobre todo en el caso del amante pero también en el del amado, quien se transforma a su vez en amante- pero sí exige no detenerse en ella. La experiencia erótica siempre se inicia en el nivel físico y al cuerpo solo debe despreciárselo en la medida en que obture nuestra compresión, nos aferre a este primer nivel de comprensión, y restrinja así la ampliación de éros hacia otras áreas existenciales, ontológicas y epistemológicas. ${ }^{51} \mathrm{El}$ cuerpo es, entonces, desvalorizado en la medida en que se lo considere únicamente un cuerpo, y, sobre todo, se reduzca la comprensión de la belleza a la estima de un cuerpo particular.

Ahora bien, el atizar en ambas partes de la relación erótica el apetito sexual sin intenciones de satisfacerlo podría entenderse como una propuesta amorosa perversa y patológica. ${ }^{52}$ Pero también puede interpretarse como el modo que tiene Platón de señalar que, aun en quien alcance la contemplación de la Forma de la belleza, el desapego completo por las instancias particulares - incluidas las de los cuerpos bellos - transformará su vida pero durará solo "un instante" (exaíphnes ${ }^{53}$ 210e), en el cual, de todos modos, se estremecerá en el éxtasis el cuerpo junto con el alma. ${ }^{54}$ Es cierto que, como ya expresara Cornford (1974, p. 143), en la filosofía de Platón, si bien "la energía que arrebata al alma en su vuelo más alto es la misma

51 En términos similares se expresa Foucault (1984, p. 258) a propósito de su análisis del éros platónico: “[Platón] no traza una línea neta, definida e infranqueable entre el mal amor del cuerpo y el buen amor del alma; por mucho que haya perdido valor y por mucho que sea inferior la relación con el cuerpo cuando se la compara con ese movimiento hacia lo bello, por peligroso que pueda ser a veces, pues puede desviarlo y detenerlo, sin embargo no se le excluye de golpe, ni se le condena para siempre".

52 Así Poratti (2010, p. 311) lo describe en estos términos: "el éros platónico [se convierte] en un juego masoquista de excitación y represión en nombre de una peraltación metafísica". No obstante, Platón matiza esta renuncia al reconocer como realización perfecta del amor en segundo grado, a continuación del amor entre filósofos, la de los enamorados que, amándose rectamente, mantienen relaciones sexuales (Phdr. 256c7-e2).

53 Sobre el sentido de exaíphnes en Platón vid. Steinhal (1993, pp. 99-105).

54 En tal sentido, incluso en interpretaciones puramente espirituales de experiencia místicas como la de Santa Teresa de Ávila, no se descarta que el cuerpo, integrado en una sola personalidad con el alma, no la acompañe con excitación sexual involuntaria en el éxtasis espiritual (Maroto, 2015, pp. 485-511). En tal respecto así describe Santa Teresa una de sus visiones místicas en El libro de la vida 29.13 (Álvarez, 2001): "Veíale [a un ángel] en las manos un dardo de oro largo, y al fin del hierro me parecía tener un poco de fuego. Este me parecía meter por el corazón algunas veces y que me llegaba a las entrañas. Al sacarle, me parecía las llevaba consigo, y me dejaba toda abrasada en amor grande de Dios. Era tan grande el dolor, que me hacía dar aquellos quejidos, y tan excesiva la suavidad que me pone este grandísimo dolor, que no hay desear que se quite, ni se contenta el alma con menos que Dios. No es dolor corporal sino espiritual, aunque no deja de participar el cuerpo algo, y aun harto" (las cursivas son mías). 
que la manifestada en los niveles inferiores por el instinto que perpetúa la raza y por las formas de ambición mundana", no se trata como en la mirada freudiana, de una sublimación ${ }^{55}$ de nuestras tendencias animales en expresiones más elevadas, puesto que:

el hombre no era para él la planta cuyas raíces están en la tierra, sino en los cielos. [...] [El alma humana] no se levanta desde abajo, sino que se hunde desde arriba cuando el espíritu se deja seducir por la carne (Cornford, 1974, p. 144).

No obstante, mientras tengamos cuerpo, el impulso erótico habrá de pergeñar nuevos ardides para cubrir su indigencia ${ }^{56}$ y realimentarse en realizaciones más o menos concretas de la belleza, entre las cuales la belleza sensible del cuerpo - frágil, efímera, diversa e impura en oposición a lo bello en sí- es el disparador más obvio y accesible, si bien la agudeza de los ojos de la razón para distinguir la hermosura en otros planos (219a; Peixoto, 2012, pp. 159-179) podría superar, andando el tiempo, el tremendo impacto de la percepción visual de lo bello (219a; Phdr. 250c8-e1).

\section{Referencias}

Álvarez, T. (2001). Santa Teresa. Obras Completas. Burgos: Monte Carmelo.

Boeri, M.D. (2016). Éros y synousía en el Simposio. En M. Tulli \& M. Erler (Eds.), Plato in Symposium. Selected Papers from the Tenth Symposium Platonicum (pp. 362-370). Sankt Agustin: Akademia Verlag.

55 Laplanche \& Pontalis (1996) definen la "sublimación" en la teoría psicoanalítica del siguiente modo: "Proceso postulado por Freud para explicar ciertas actividades humanas que aparentemente no guardan relación con la sexualidad, pero que hallarían su energía en la fuerza de la pulsión sexual. Freud describió como actividades de resorte principalmente la actividad artística y la investigación intelectual. Se dice que la pulsión se sublima, en la medida en que es derivada hacia un nuevo fin, no sexual, y apunta hacia objetos socialmente valorados". Al respecto debe notarse, tal como señalan estos mismos autores, que en Freud la palabra "sublime" evoca a la vez la producción en el ámbito de las bellas artes que sugiere grandeza, elevación, así como también el proceso que hace pasar directamente un cuerpo del estado sólido al estado gaseoso en la química. Es esta última a partir de la cual probablemente Freud construye esta noción. Vid. LP u.v. "sublimación".

56 En tal sentido señala Ostenfeld (1992, pp. 324-328) a propósito del Fedro que la parte apetitiva del alma - tò epithymetikón -, que es la más obviamente conectada al cuerpo y sus deseos, es la que asegura la actividad permanente de Éros - y con ello el auto-movimiento permanente del alma y su ciclo de reencarnaciones - en el universo, en la medida que en el plano de los apetitos, indefectiblemente, la carencia constitutiva de éros no puede ser superada en términos absolutos. 
Burnet, I. (1899-1906). Platonis Opera, 5 vols. Oxford: Oxford University Press.

Bury, R. G. (1932). The Symposium of Plato. Cambridge: W. Heffer \& Sons.

Brisson, L. (1998). Plato. Le Banquet. Paris: Le Belles Lettres.

Broadie, S. (2001). Soul and body in Plato and Descartes. Proceedings of the Aristotelian Society, 101, 295-308.

Calame, C. (2002). Eros en la antigua Grecia. Roma: Akal.

Candiotto, L. (2015). Plato's cosmological medicine in the discourse of Eryximachus in the Symposium. The responsibility of a harmonic techne. Plato Journal, 5, 81-93.

Casertano, G. (1997). Il (in) nome di Eros. Una lettura del discorso di Diotima nel Simposio platónico. Elenchos, 18, 277-310.

Cornford, F. (1974). La doctrina de éros en el Banquete de Platón. La filosofía no escrita (A. Pérez Ramos, Trad.). Barcelona: Ariel.

Davidson, J. N. (1997). Courtesans and fishcakes: the consuming passions of Classical Athens. Chicago: St. Martin's Press.

Di Benedetto, V. (1986). Platone. Simposio. Milán: Bur.

Diccionario de la Real Academia Española (23 ed.). (2014). Madrid: Real Academia Española (DRAE).

Diniz Peixoto, M. C. (2012). Corpo, anima, visibile e invisibile nel Simposio platónico. En A. Borges de Araújo Jr. \& G. Cornelli (Eds.), Il Simposio di Platone: un banchetto di interpretazioni (pp. 159-180). Napoli: Loffredo University Press.

Dixsaut, M. (2001). Les metamorphoses de la dialectique dans les dialogues de Platon. Paris: Vrin.

Dover, K. J. (1966). Aristophanes's speech in Plato's Symposium. Journal of Hellenic Studies, $66,41-50$.

Dover, K. J. (1978). Greek Homosexuality. London: Duckworth.

Dover, K. J. (1980). Plato's Symposium. Cambridge; New York: Cambridge University Press.

Dorter, K. (1969). The Significance of the Speeches in Plato's Symposium. Philosophy and Rhetoric, 2(4), 215-234.

Eggers Lan, C. (1983). El Fedón de Platón. Buenos Aires: Eudeba.

Fierro, M. A. (2013a). Two conceptions of the body in Plato's Phaedrus. En G. Boys-Stones, D. El-Murr \& C. Gill (Eds.), The Platonic Art of Philosophy (pp. 27-50). Cambridge: Cambridge University Press.

Fierro, M. A. (2013b). Alma encarnada - cuerpo amante en el Fedón de Platón. En Benítez Grobet, L. \& Velázquez Zaragoza, A. (Eds.), Platonismo y neoplatonismo en la modernidad filosófica (pp. 7-42). México D.F: Ediciones de La Torre.

Fierro, M. A. (2013c). Loving and lovable bodies in Plato's Symposium, XI Symposium Platonicum: The "Symposium". Proceedings II (pp. 258-262). Pisa: International Plato Society - Universidad de Pisa.

Fierro, M. A. (2015a). Éros y sôma en el Banquete de Platón, P. Spangenberg \& R. Braicovich (Eds.), Actas del II Simposio de la Asociación Argentina de Filosofía Antigua. Conocimiento, 
ética y estética en la Filosofía Antigua (pp. 125-132). Buenos Aires: Asociación Argentina de Filosofía Antigua.

Fierro, M. A. (2015b). Élenchos y éros: el caso de Sócrates y Agatón en Smp. 199c-201a. Archai Journal: on the Origins of Western Thought, 14, 93-108.

Foucault, M. (1984). Historia de la sexualidad: el uso de los placeres (S. Martí, Trad.). México D.F.: Siglo XXI.

García Gual, C. (2006). El último poema de Safo. Letras vivas, 58, 43-45.

Gallop, D. (1975). Plato - Phaedo (Transl. and notes). Oxford: Oxford University Press.

Gill, C. (1990). Platonic Love and Individuality. En A. Loizou and H. Lesser (Eds.), Polis and Politics: Essays in Greek Moral and Political Philosophy (pp. 69-88). Hants: Aldershot.

Gill, C. (1999). Plato's Symposium. London: Penguin Books.

Gould, Th. (1963). Platonic love. New York: The Free Press of Glencoe.

Hackforth, R. (1952). Plato's Phaedrus (Translation and commentary). Cambridge: The BobbsMerrill Company.

Hunter, R. (2004). Plato's Symposium. Oxford: Oxford University Press.

Holmes, B. (2010). The symptom and the subject: the emergence of physical body in Ancient Greece. Princeton: Princeton University Press.

Jaeger, W. (1957). Paideia. Los ideales de la cultura griega. México: Fondo de Cultura Económica.

Juliá, V. (2004). Platón. Banquete. Buenos Aires: Losada.

Kilmer, M. F. (1993). Greek Erotica on Attic Red-figure Vases. London: Duckworth.

Konstan, D. (2012). El concepto de belleza en el mundo antiguo y su recepción en Occidente, Nova Tellus, 30(1), 133-148.

Krishnamurti, J. (2009). Sobre la educación. Barcelona: Kairós.

Laplanche, J. \& Pontalis, J. B. (1996). Diccionario de Psicoanálisis, (F. G. Cervantes, Trad.). Buenos Aires: Paidós (= LP).

Larsson, K. (2008). ¿Qué es yoga? Reflexiones acerca del significado del Yoga. Buenos Aires: De los Cuatro Vientos.

Lasserre, F. (1944). Erotikoí lógoi, Museum Helveticum, 1, 169-178.

Lewis, C. J. (1964). A grief observed. London: Faber \& Faber.

Liddell, H. G., Scott, R. \& Jones, H. (1940). Greek English Lexicon. Oxford: The Clarendon Press $(=L S J)$.

Maroto, Daniel de Pablo (2015). Éxtasis místico, sexualidad y Santa Teresa. Revista de Espiritualidad, 74, 485-511.

Marrou, H-E. (1985). Historia de la educación en la antigüedad. Akal: Buenos Aires.

Moravscik, J. (1971). Reason and Eros in the Ascent Passage of the Symposium. En J. P. Anton and G. L. Kustas (Eds.), Essays in Ancient Greek Philosophy, volume 1 (pp. 285-303). Albany: State University of New York Press.

Moreau, J. M. (1962). Aristóteles y su escuela, (M. Ayerra, Trad.). Buenos Aires: Eudeba.

Von Möllendorff, P. (2009). Man as Monster: Eros and Hubris in Plato's Symposium. In T. Fögen 
\& M. M. Lee (Eds.), Bodies and Boundaries in Graeco-Roman Antiquity (pp. 87-109). Berlin / New York: De Gruyter.

Neumann, H. (1964). On the Sophistry of Plato's Pausanias. Transactions and Proceedings of the American Philological Association, 95, 261-267.

Nightingale, A. W. (1995). Genres in dialogue. Plato and the Construct of Philosophy. Cambridge: Cambridge University Press.

Nightingale, A. W. (2004). Chapter 4: Theorizing the beautiful body: from Plato to Philip of Opus. En Nightingale, A.W. (2004), Spectacles of Truth in Classical Greek Philosophy. Theoria in its Cultural Context (pp. 139-186). Cambridge: Cambridge University Press.

Nussbaum, M. (2001). The Fragility of Goodness (updated edition). Cambridge: Cambridge University Press.

Ostenfeld, E. N. (1982). Forms, Matter and Mind: Three Strands in Platonic Metaphysic. The Hague: Nighoff.

Ostenfeld, E. N. (1987). Ancient Greek Philosophy and the Body-Mind Debate. Dinamarca: Aarhus University Press.

Ostenfeld, E. N. (1992). Self-motion, tripartition and embodiment. In L. Rossetti, Understanding the "Phaedrus" (pp. 324-328). Sank Agustin: Academia Verlag.

Penner, T. (2007). The Death of the so-called 'Socratic Elenchus'. In Erler, M. \& Brisson, L. (Eds.), Gorgias-Menon: Selected Papers from the Seventh Symposium Platonicum (pp. 3-19). Sank Agustin: Akademia Verlag.

Poratti, A. (1993). Diálogo, comunidad y fundamento. Política y metafísica en el Platón inicial. Buenos Aires: Biblos.

Poratti, A. (2010). Platón. Fedro. Madrid: Akal.

Parry, R. D. (2016). Eryximachus' Physical Theory in Plato's Symposium. En M. Tulli \& M. Erler (Eds.), Plato in Symposium. Selected Papers from the Tenth Symposium Platonicum (pp. 160-174). Sankt Agustin: Academia Verlag.

Pender, E. (1992). Spiritual pregnancy in Plato's Symposium. Classical Quaterly, 42, 72-86.

Reale, G. (2004). Eros, demonio mediador. El juego de las máscaras en el Banquete de Platón, (R. Ruis y P. Salva, Trad.). Barcelona: Herder.

Reeve, C. D. C. (1992). Telling the Truth About Love: Plato's Symposium. Proceedings of the Boston Area Colloquium in Ancient Philosophy, 8, 89-114.

Regali, M. (2016). La mimesis di sé nel discorso di Agatone: l'agone fra poesia e filosofia nel Simposio. En M. Tulli \& M. Erler (Eds.), Plato in Symposium. Selected Papers from the Tenth Symposium Platonicum (pp. 204-208). Sankt Agustin. Academia Verlag.

Renaut, O. (2016). La péderastie selon Pausanias: un défi pour 1'education platonicienne. En M. Tulli \& M. Erler (Eds.), Plato in Symposium. Selected Papers from the Tenth Symposium Platonicum (pp. 140-147). Sankt Agustin: Academia Verlag.

Robin, L. (1951). Platon. Le Banquet. Paris: Les Belles Lettres.

Robinson. R. (1953). Elenchus. Plato's Earlier Dialectic (pp. 7-49). Oxford: Oxford University Press. 
Robinson, T. M. (1995). Plato's Psychology. Toronto: University of Toronto Press.

Rowe, C. J. (1998). Plato. Symposium. Warminster: Aris \& Phillips Ltd.

Rowe, C. J. (1999). The Speech of Eryximachus in Plato's Symposium. En J. J. Cleary (Ed.), Traditions of Platonism: Essays in Honour of John Dillon (pp. 53-64). Aldershot: Ashgate.

Sheffield, F. C. C. (2001). Alcibiades' Speech: A Satyric Dramaj. Greece \& Rome, 48(2), 193-209.

Sheffield, F. C. C. (2006). Plato's Symposium. The Ethics of Desire. Oxford: Oxford Classical Monographs.

Scolnicov, S. (2016). What Socrates Learned from Aristophanes (and What He Left Behind). En M. Tulli \& M. Erler (Eds.), Plato in Symposium. Selected Papers from the Tenth Symposium Platonicum (pp. 178-182). Sankt Agustin: Academia Verlag.

Scheffield, F. (2006). The Role of the Earlier Speeches in the Symposium: Plato's Endoxic Method? In J. Lesher et al., Plato's Symposium. Issues in Interpretation and Reception (pp. 23-46). Washington D.C.: Harvard University Press.

Soares, L. (2009). Estudio preliminar: La erótica platónica en perspectiva. En Mársico, C., Platón. Banquete (pp. 13-128). Buenos Aires: Miluno.

Snell. B. (1953). The Discovery of the Mind: The Greek Origins of European Thought. Oxford: Basil Blackwell.

Stalley, R. (2016). Sophrosyne in the Symposium. En M. Tulli \& M. Erler (Eds.), Plato in Symposium. Selected Papers from the Tenth Symposium Platonicum (pp. 165-171). Sankt Agustin: Academia Verlag.

Steinthal, H. (1993). Mógis und exaíphnes: Platon über die Grenzen des Erkennens, Festschrift für W. Heilman zum 65. Geburstag (pp. 99-105). Frankfurt am Main: Diesterweg.

Vlastos, G. (1973). The Individual as an Object of Love. In G. Vlastos, Platonic Studies (pp. 3-42). Princeton: Princeton University Press.

Vlastos, G. (1983). The Socratic Elenchus. Oxford Studies in Ancient Philosophy (pp. 28-57). Oxford: Oxford University Press.

Wardy, R. (2012). Father of the Discourse: Phaedrus' Speech in the Symposium. Revue de Philosophie Ancienne, 30(2), 133-184. 